\title{
SPECIATION OF HEAVY METALS IN BOTTOM SEDIMENTS OF KARRA RIVER, NEPAL
}

\author{
ABSTRACT \\ The chemical forms of copper and zinc have been determined using the \\ fractional scheme of Tessier et al. (1979) in the bed sediments of Karra River, \\ Hetauda, Nepal. The sequential extraction revealed that high percentage of metals \\ was associated in the residual fraction (upstream and downstream). However, in most \\ of the sites in the industrial belt, a significant proportion of metal was associated with \\ the non-residual fraction (64\% in $\mathrm{Cu}$ and $45 \%$ in $\mathrm{Zn}$ ) which can be remobilized and \\ released to the environment by various physical-chemical processes. This indicates \\ influence of anthropogenic activities on the Karra River.
}

Sadhana Pradhanang*

Key words: Chemical form, bed sediment, Karra, industrial belt, anthropogenic INTRODUCTION

Sediment is an important source of heavy metal pollutants in a river ecosystem as they have a long residence time (Forstner and Wittmann, 1983). Sediment serves as a sink where contaminants can be stored and also act as a source of the pollutants to the overlying water and to the aquatic organism of the ecosystem. Therefore, it serves as the carrier and reservoir of the heavy metals and reflects the quality of the system (Chapman and Wang, 1999). Heavy metals are not permanently fixed on sediments and can be released back to the water column by changes in environmental conditions, such as $\mathrm{pH}$, redox potential, and chelation in the aquatic environment (Forstner, 1987; Sutherland and Tack, 2007; Rath, et al., 2009). It provides a qualitative idea about reactivity and mobility of total metals present in sediments (Vicente-Beckett, 1991). The mobility of metals in the environment depends on their chemical forms or type of the binding of the element. Sediments are good indicator of water quality and reflect the effects of anthropogenic release. Numerous studies have been conducted on heavy metal pollution from different anthropogenic sources (Ma and Rao, 1997). It is important to know not only the total metal content but also the site of the metal in the sediment matrices (exchangeable, carbonate, Fe-Mn oxides, organic, residual fraction) which probably indicates the occurrence of different pollution sources (Jain et al., 2004).

The method of fractionation of trace metals in sediments are based on sequential extraction procedures. Sequential extraction is used to determine geochemical partitioning of heavy metals in soil, sediments and sludge (Howard and Shu, 1996). So it is widely used to estimate the amounts and proportions of metals in soil and to predict bio-availability and metal leaching (Jalali and Khanlari, 2008). The unbuffered salts, weak acids, reducing agents, oxidizing agents, and strong acids are generally used as extractant in sequential extraction (Filgueiras, 2002; Tessier and Cambell, 1987). In the present study, sequential extraction was carried out in five step procedures as proposed by Tessier et al. (1979)

Dr. Pradhanang is an Associate Professor at Central Department of Environmental Science, T.U., Kirtipur, Nepal. 
which was followed to determine the partitioning of the trace metals $\mathrm{Cu}$ and $\mathrm{Zn}$, The five step geochemical fractions including exchangeable, carbonates (acid-soluble), iron-manganese oxide bound (reducible), organic matter bond (oxidisable) and residual fractions (ssilicate fraction).

\section{MATERIALS AND METHODS}

SAMPLING

A total 12 sampling sites for river bed sediment samples were selected along the bank of the Karra River, Hetauda, Nepal. The samples selected from its upstream, industrial belt and downstream portions of the Karra River. The sediment samples were collected in the month of May 2012. Bed sediment samples were collected manually with the help of plastic scraper and spatula from the uppermost 5 to $10 \mathrm{~cm}$ of the river bank where flow was low. Three random samples were taken from each site, which were homogenized and composite samples were stored in plastic bag with zip lock.

\section{METAL FraCtionation}

Air dried sediments samples were ground using a mortar pestle to a size about $63 \mu \mathrm{m}$ and subjected to the following extractions. All the extractions, except the final digestion, were conducted in $50 \mathrm{ml}$ polypropylene centrifuge tubes to minimize losses of solid materials. After each successive extraction, the supernatant was separated by centrifuging at $7000 \mathrm{rpm}$ for 30 minutes. The supernatant obtained in each of the extractions were collected. The residue was washed with $10 \mathrm{ml}$ milli-Q water followed by centrifugation for 1 hour before the next extraction. In the extraction two metals (viz; $\mathrm{Cu}, \mathrm{Zn}$ ) were analyzed by five steps sequential extraction procedure proposed by Tessier et al. (1979).

Exchangeable: One gram sediment sample was extracted at room temperature for one hour with $8 \mathrm{ml}$ of $1 \mathrm{M} \mathrm{MgCl}_{2}(\mathrm{pH} 7.0)$ with continuous agitation.

Bound to carbonates: The residue obtained from step (1) was leached at room temperature with $8 \mathrm{ml}$ of $1.0 \mathrm{M}$ sodium acetate adjusted to $\mathrm{pH} 5.0$ with acetic acid. The mixture was agitated for 5 hours.

Bound to Fe-Mn Oxides: The residue obtained from step (2) through continuous agitation at $96^{\circ} \mathrm{C}$ with $20 \mathrm{ml}$ of $0.04 \mathrm{M} \mathrm{NH}_{2} \mathrm{OH} . \mathrm{HCl}$ in $25 \%(\mathrm{v} / \mathrm{v})$ acetic acid for 6 hours.

Bound to organic matter: The residue obtained from step (3), $3 \mathrm{ml}$ of $0.02 \mathrm{M} \mathrm{HNO}_{3}$ and $5 \mathrm{ml}$ of $30 \% \mathrm{H}_{2} \mathrm{O}_{2}$ were added and $\mathrm{pH}$ adjusted to $\mathrm{pH} 2.0$ with $\mathrm{HNO}_{3}$. The solution was agitated at $96^{\circ} \mathrm{C}$ for 2 hours and $3 \mathrm{ml}$ of $30 \% \mathrm{H}_{2} \mathrm{O}_{2}(\mathrm{pH}$ 2 with $\mathrm{HNO}_{3}$ ) was added and sample was again agitated for 3 hours. After cooling, $5 \mathrm{ml}$ of $3.2 \mathrm{M}$ ammonium acetate in $20 \%(\mathrm{v} / \mathrm{v}) \mathrm{HNO}_{3}$ was added. The sample was diluted to $20 \mathrm{ml}$ and agitated continuously for 30 minutes. The filtrate obtained in each step of the extraction was analyzed for heavy metals.

Residual: Residual obtained from step 4 was digested with $\mathrm{HF} / \mathrm{HNO}_{3} / \mathrm{HClO}_{4}$ mixture. $100 \mathrm{mg}$ of residue was taken in a Teflon beaker and $20 \mathrm{ml}$ of acid mixture of $\mathrm{HF}, \mathrm{HNO}_{3}$ and $\mathrm{HClO}_{4}$ (in the ratio 7:3:1) was added. The Teflon beaker was placed in bomb digestion unit and heated $100^{\circ} \mathrm{C}$ for 2 hours. After cooling, volume was made up to $250 \mathrm{ml}$ by adding milli-Q water. Moreover, to ensure 
the comparison of total metals to residual fraction, the procedure for the residual fraction was same to the method for the total metal determination.

The total metal concentrations were also determined by the acid digestion method using $\mathrm{HF}, \mathrm{HNO}_{3}$ and $\mathrm{HClO}_{4}$ in the ratio of 7:3:1.

\section{METAL ION ANALYSIS}

Metal ion concentrations in different extracts were determined by Shimadzu Atomic Absorption spectrophotometer (model AA-6000) using airacetylene flame. Quantification of metals was based upon calibration of standard solution of respective metals. These calibration curves were determined several times during the period of analysis. The precision of the metal analysis was controlled by including triplicate samples in analytical batches and blank. The detection limits of copper and zinc are $0.1 \mu \mathrm{gL}^{-1}$, respectively.

\section{RESULTS AND DISCUSSION}

Copper was observed in varying proportion in all phases in the upstream of the Karra River. $\mathrm{Cu}$ was found to be $78.6 \%$ of the total metal $(69.3$ $\mathrm{mg} / \mathrm{kg}$ ) which were predominantly in the residual form (Fig. 1). Much lower concentration were associated with exchangeable and carbonate fractions of the total metal. The contribution of Fe-Mn oxides and organic fraction to total metal was $6.3 \%$ and $3.4 \%$ (Fig. 1 ).

In the industrial belt, $\mathrm{Cu}$ fractions were distributed in exchangeable $(6 \%)$, carbonate $(5.5 \%)$, Fe-Mn oxides $(26.3 \%)$, organic $(27.0 \%)$ and residual $(35.1 \%)$ of the total metal $(312 \mathrm{mg} / \mathrm{kg})$. For $\mathrm{Cu}$, bound to organic matter $(27 \%)$ was the highest due to the high affinity of $\mathrm{Cu}$ for organic matter (McGrath, and Quevanviller, 1996). Large variation of $\mathrm{Cu}$ percentage could be found in different fractions at the different sites of the industrial belt. The maximum fraction was bound to organic fraction as well as reducible fraction. Results of the downstream samples have shown that percentage of $\mathrm{Cu}$ extracted in different steps are as: exchangeable $(1.8 \%)$, carbonate $(1.5 \%)$, Fe-Mn oxides $(9.9 \%)$, organic $(7 \%)$ and residual $(79.8 \%)$ of the total metal $(264 \mathrm{mg} / \mathrm{kg})$.

Zinc is one of the most commonly occurring heavy metals which are soluble and mobile under acidic condition. Zinc enters surface waters mostly from metals treatment plants and chemical plants. The results show that in the upstream of the Karra River, Zn concentrations were $3.8 \%$ and $4.9 \%$ of the total metal $(67.48 \mathrm{mg} / \mathrm{kg})$ in exchangeable and carbonate fraction, respectively. Concentration of $\mathrm{Zn}$ at the upstream has been found to differ in Fe-Mn oxides and organic and residual fractions (Fig. 1). The concentration was high in the Fe-Mn oxide fraction (32.9\%) and much lower $(2.4 \%)$ in the organic fraction whereas the residual fraction was $56.0 \%$ of the total metal. In the industrial belt, under different fractions, percentage of total $\mathrm{Zn}$ extracted were $5.3 \%, 8.9 \%, 22.0 \%, 8.8 \%$ and $55 \%$, respectively in exchangeable, carbonate, Fe-Mn oxides, organic and residual fraction. In the non-residual fraction, the mean concentration of $\mathrm{Cu}(64 \%)$ and $\mathrm{Zn}(45 \%)$ were found to be the highest of the total metal. High $\mathrm{Zn}$ fraction of Fe-Mn oxide indicates anthropogenic origin. In the downstream, high concentration of $\mathrm{Zn}(50 \%)$ was found in residual of the total metal 
$(1396 \mathrm{mg} / \mathrm{kg})$. The general association of $\mathrm{Zn}$ was in the decreasing order: residual $>$ Fe-Mn oxides $>$ organic $>$ carbonate $>$ exchangeable.
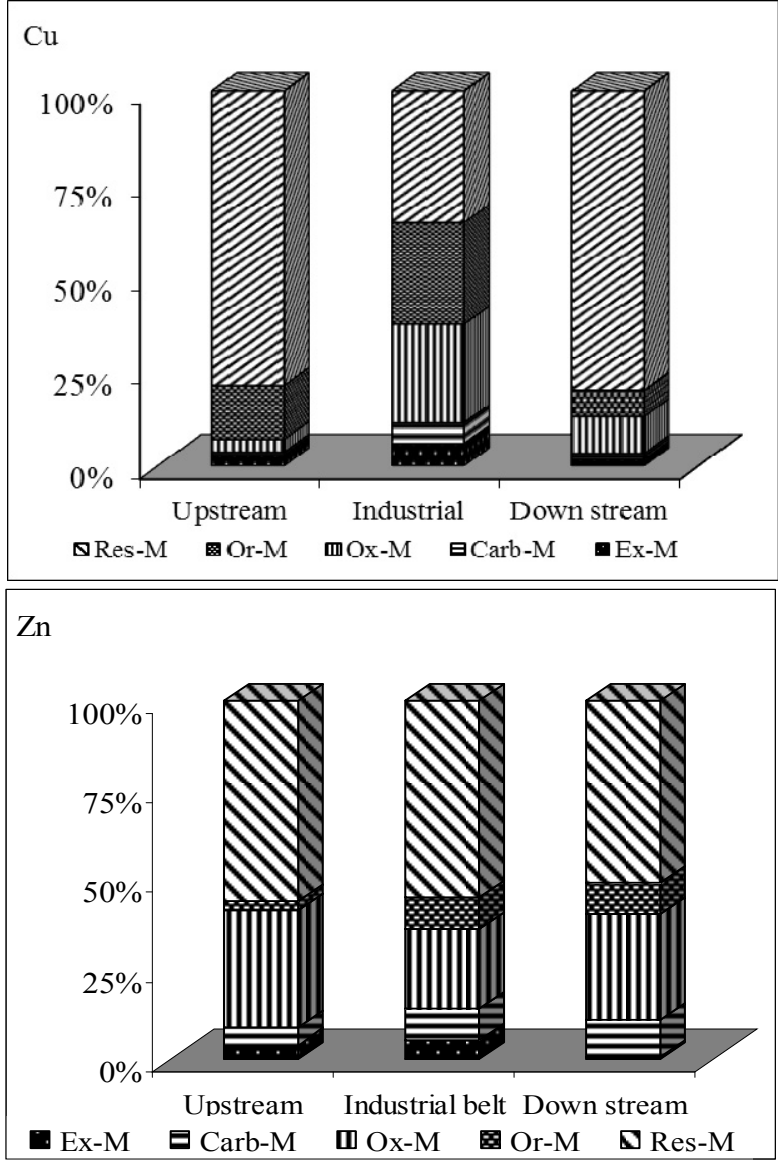

Figure1: Metal fraction in bed sediments of the Karra River (Exchangeable, carbonate, Fe-Mn oxide, organic and residual).

\section{RECOVERY OF THE METAL}

The accuracy of the sequential extraction procedure, recovery values (\%) were calculated by comparing the sum of five- steps sequential extraction procedure (exchangeable, carbonate, reducible, organic and residue) with the total metal concentration.

The recovery of the sequential extraction was calculated as follows:

$$
\text { Recovery }_{n}=\frac{\sum_{n} \text { Sequential extraction }}{\text { Total metal digestion }} \times 100
$$


The results of recovery showed in Table 1 which indicates that sums of the five fractions with the good recoveries (92.21-106.29\%).

Table1: Recovery of the metals

\begin{tabular}{|c|c|c|c|c|c|c|}
\hline \multirow[b]{2}{*}{$\begin{array}{c}\text { Sample } \\
\text { sites }\end{array}$} & \multicolumn{3}{|c|}{$\mathbf{C u}$} & \multicolumn{3}{|c|}{ Zn } \\
\hline & $\begin{array}{l}\text { Sum of } \\
\text { the } \\
\text { extraction } \\
\text { steps of } \\
\text { metal } \\
(\mathrm{mg} / \mathrm{kg})\end{array}$ & $\begin{array}{c}\text { Total } \\
\text { metal } \\
(\mathrm{mg} / \mathrm{kg})\end{array}$ & $\begin{array}{c}\text { Recovery } \\
\%\end{array}$ & $\begin{array}{c}\text { Sum of } \\
\text { the } \\
\text { extraction } \\
\text { steps of } \\
\text { metal } \\
(\mathrm{mg} / \mathrm{kg})\end{array}$ & $\begin{array}{c}\text { Total } \\
\text { metal } \\
(\mathrm{mg} / \mathrm{kg})\end{array}$ & $\begin{array}{c}\text { Recovery } \\
\%\end{array}$ \\
\hline US1 & 73.11 & 70.42 & 103.82 & 47.88 & 52.67 & 90.91 \\
\hline US2 & 65.54 & 70.09 & 93.50 & 87.08 & 93.79 & 92.85 \\
\hline IB1 & 128.08 & 130.89 & 97.85 & 64.16 & 68.26 & 94.00 \\
\hline IB2 & 71.70 & 74.87 & 95.77 & 37.69 & 35.46 & 106.29 \\
\hline IB3 & 108.92 & 104.81 & 103.92 & 50.07 & 49.08 & 102.02 \\
\hline IB4 & 218.96 & 230.86 & 94.85 & 161.07 & 172.18 & 93.55 \\
\hline IB5 & 607.17 & 657.89 & 92.29 & 200.47 & 218.52 & 91.74 \\
\hline IB6 & 1165.93 & 1142.52 & 102.05 & 282.01 & 305.21 & 92.40 \\
\hline IB7 & 711.50 & 732.65 & 97.11 & 143.19 & 154.51 & 92.67 \\
\hline IB8 & 198.17 & 189.99 & 104.31 & 845.46 & 946.01 & 89.37 \\
\hline IB9 & 106.34 & 110.97 & 95.82 & 267.06 & 290.77 & 91.85 \\
\hline IB10 & 91.51 & 89.96 & 101.72 & 851.26 & 840.39 & 101.29 \\
\hline IB11 & 174.66 & 182.13 & 95.90 & 1476.82 & 1444.50 & 102.24 \\
\hline IB12 & 169.33 & 180.26 & 93.93 & 1810.09 & 1989.10 & 91.00 \\
\hline DS1 & 316.52 & 329.17 & 96.16 & 770.37 & 835.41 & 92.21 \\
\hline DS2 & 211.60 & 207.76 & 101.85 & 2021.61 & 1987.77 & 101.70 \\
\hline
\end{tabular}

CONCLUSION

The Karrra River is used as a water recreational, washing and agricutural purposes. A number of industries do not have proper waste water treatment plant facilities and waste goes directly or indirectly into the Karra River and thus the river is more or less becoming a dumping site of a variety of organic and inorganic chemicals.

A sequential extraction procedure was used to fractionate, $\mathrm{Cu}$, and $\mathrm{Zn}$ present in twelve sediment samples. The results of the present study indicate that residual fraction is the most dominant fraction for all the metals. However, in most of the sites in the industrial belt, a significant proportion of metal was associated with the non-residual fraction. This indicates influence of anthropogenic activities on the Karra River. In the upstream of the Karra river, high concentration of metal present are in inert phase (residual), being detrital and of lattice origin (Salomons and Forstner, 1980). The residual fraction was the most abundant fraction for all the metals in the sediment studied. A significant amount of $\mathrm{Zn}$, and $\mathrm{Cu}$ was associated with the non-residual fractions in industrial belt studied indicating that this metal was potentially more bio-available than other metals. The low percentage of heavy metals in the exchangeable fraction suggests week bioavailability of metal in this environment. 


\section{WORKS CITED}

Chapman, P.M., Wang, F.Y. (1999). Appropriate applications of sediments quality values for metals and metalloids. Environmental Science and Technology. 33:3937-3941.

Filgueiras, A.V., Lavilla, I., Bendicho, C. (2002). Chemical sequential extraction for metals partitioning in environmental solid samples. Journal of Environmental Monitoring. 4:823-857.

Forstner, U. (1987). In Metal Speciation, Separation and Recovery. Lewis Publishers, Chelsea.

Forstner, U., Wittman, G.T. (1983). Metal Pollution in the Aquatic Environment. Springer Verlag, Berlin.

Gadde, R.R. and Laitinen, H.A. (1974). Studies of heavy metal adsorption by hydrous iron and manganese oxides. Analytical Chemistry. 46:2022- 2026.

Howard, J.L. and Shu, J. (1996). Sequential extraction analysis of heavy metals using a chelating agent (NTA) to counteract resorption. Environmental Pollution. 91:89-96.

Jain, C. K., Singhal, D.C., and Sharma, M.K. (2004). Adsorption of zinc on bed sediment of River Hindon: adsorption models and kinetics. Journal of Hazardous Materials. 114:231-239.

Jalali, M. \& Khanlari, Z.V. (2008). Environmental contamination of Zn, Cd, Ni, $\mathrm{Cu}$, and $\mathrm{Pb}$ from industrial areas in Hamadan Province, western Iran. Environmental Geology. 55:1537-1543.

Ma, L.Q., and Rao, G.N.(1997). Chemical fractionation of cadmium, copper, nickel and zinc in contaminated Soils. Journal of Environmental Quality. 26: 259-264.

McGrath, D., Quevanviller, P. (1996). Application of single and sequential extraction procedures to polluted and unpolluted soils. Science of the Total Environment. 178: 37-44.

Rath, P., Panda, U.C., Bhatta, D., Sahu, K.C. ( 2009) Use of sequential leaching, mineralogy, morphology and multivariate statistical technique for quantifying metal pollution in highly polluted aquatic sediments-a case study: Brahmani and Nandira Rivers. India Journal of Hazardous Materials. 163: 632-644.

Salomons, W., Forstner, U. (1984). Metals in Hydrocycle. Springer, New York.

Sutherland, R.A., Tack, F.M.G. (2007). Sequential extraction of lead from grain size fractionated river sediments using the optimized BCR Procedure. Water Air Soil Pollution. 84: 269-284.

Tessier, A., Campbell, P.G.C. (1987). Partitioning of trace metals in sediments: relationships with bioavailability. Hydrobiologia, 149: 43-42.

Tessier, A., Cambell, P.G.C., Bisson, M.X. (1979), Sequential extraction procedure for the speciation of particulate trace metals. Analytical Chemistry. 51: 844-851.

Vicente-Beckett, V.A., Pascual, C.B., Kwan, C.S., Beckett. (1991). Levels and distribution of trace metals in sediments of Laguna Lake (Philippines) and its tributary rivers. International Journal of Analytical Chemistry. 45: 101-116. 